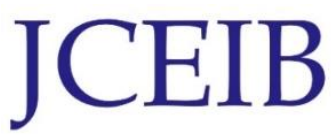

Journal Chemical Engineering and Industrial Biotechnology (JCEIB)

Open Access

Volume 3 pp. 1-16; March 2018

CUniversiti Malaysia Pahang Publisher

DOI: https://doi.org/10.15282/JCEIB-V3-01.28/3/2018/3.3

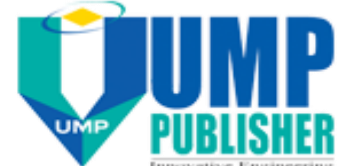

\title{
OPTIMIZATION OF BORON REMOVAL FROM AQUEOUS SOLUTION VIA ADSORPTION USING COMPOSITE BEADS OF MANGROVE BARK, ALGINATE AND ZEOLITE
}

\author{
Che Ku Nur Aima Che Ku Mohd ${ }^{\mathrm{a}^{*}}$, Mohd Halim Shah Ismail ${ }^{\mathrm{a}}$ \\ ${ }^{a}$ Department of Chemical and Environmental Engineering, Faculty of Engineering, Universiti Putra \\ Malaysia, 43400 UPM Serdang, Selangor, Malaysia. \\ *Corresponding author: E-mail: aimamohd_upm@yahoo.com \\ Tel.: +60138180109
}

\begin{abstract}
The presence of boron beyond the allowable limit in water bodies can pose a dangerous risk to all living organisms. In order to increase the adsorption capacities of composite beads of mangrove bark, alginate and zeolite (MAZC) to remove boron from aqueous solution, pretreatment of mangrove bark using sodium hydroxide solutions at a temperature of $60^{\circ} \mathrm{C}$ was conducted. The surface characterizations of the beads were conducted using Fourier transform infrared spectroscopy (FTIR), Brunauer-Emmett Teller (BET) and scanning electron microscope with energy dispersive X-ray spectroscopy (EDX) before and after boron adsorption. The results showed that the BET surface area of MAZC beads increased due to modification of the mangrove bark during pretreatment process. The effects of $\mathrm{pH}$, temperature, adsorbent dosage and contact time on the boron uptake were then evaluated using batch studies. It was found that the maximum adsorption of boron was $83.3 \%$ occurred at $\mathrm{pH} 5,24 \mathrm{~h}$ contact time, $12 \mathrm{~g}$ of adsorbent dosage and at a temperature of $27^{\circ} \mathrm{C}$. Thermodynamic studies indicated the spontaneous and exothermic nature of adsorption process. Langmuir isotherm model best described the experimental adsorption data with maximum adsorption capacities of $6.964 \mathrm{mg} / \mathrm{g}$. The kinetic data were best described by the pseudo-second order model $\left(\mathrm{R}^{2}=0.9998\right)$. These results indicate that the pretreatment of mangrove bark can optimize the removal of boron from aqueous solution.
\end{abstract}

Keywords: Boron; adsorption; mangrove; isotherm study; kinetic study.

\subsection{INTRODUCTION}

Malaysia is a well-known global exporter of petrochemical products. The key reasons attributed to the rapid growth of this industry are the availability of oil and gas as feedstock, well-developed infrastructure and a strong base of supporting services (Foo \& Eng, 2015). The industry nevertheless constantly produces a substantial amount of wastewater which holds various pollutants as a result of chemical processes. Among the elements found in the petrochemical effluent is boron (Ismail et al., 2013). Boron and its compounds have also been popularly used as one of the chemicals involved in hydraulic fracturing as a crosslinking agent (Sari \& Chellam, 2015), during oxidation of hydrocarbons and as a catalyst (Thompson, 1974). The highest limit of boron needed by an adult human being is only $20 \mathrm{mg} /$ day and it can be toxic beyond this limit. World Health Organization (WHO) has suggested the amount of boron in drinking water must 
be below $2.4 \mathrm{mg} / \mathrm{L}$. In Malaysia, Malaysia Environmental Quality Regulation set that the acceptable limit for boron discharge from industrial wastewater has to be limited to only $4 \mathrm{mg} / \mathrm{L}$. Therefore, removal of boron from the petrochemical wastewater is paramount prior to discharging it into the stream or river.

A number of technologies have been developed to remove boron from wastewater such as chemical precipitation (Shih et al., 2014), reverse osmosis (Rahmawati et al., 2012), ion exchange (Yilmaz et al., 2005) and ultrafiltration (Yürüm et al., 2013). However, most of these conventional treatments are ineffective for low concentration of metals ions, involve sludge disposal problems and incur high cost to be practised (Mirbagheri \& Hosseini, 2005). Of many separation techniques, adsorption has received generous attention from the industrial players due to its process simplicity and low-cost characteristics. Activated carbon (Kluczka et al., 2007), fly ash (Öztürk \& Kavak, 2005), modified clays (Karahan et al., 2006), palm seed ash (Al.Haddabi et al., 2016) and mineral sorbents (Jalali et al., 2016) are some adsorbents used in previous studies for boron removal.

This study proposes to develop a novel composite adsorbent which is made up of mangrove bark (Rhizophora apiculata), sodium alginate and natural zeolite. In Malaysia, mangrove bark can be easily obtained from timber industry at a low price and has proven to have good adsorption ability on the removal of heavy metal. The performance of the mangrove can further be enhanced by treating the bark with suitable chemicals such as acid or base to increase the proportion of actives surfaces and to avoid leaching of tannin compounds (Emin Argun \& Dursun, 2006). Alginate, the main component of brown algae is a polysaccharide biopolymer consist of anionic blocks of 1,4 linked $\mathrm{d} \alpha$-L-gluronic acid (G) and $\beta$-D-mannuronic acid (M) (Papageorgiou et al., 2006). Alginate is a very potent metal chelator and has a gelling ability which enables it to act as a binder. Zeolite is microporous crystalline aluminosilicates where aluminium, silicon and oxygen are arranged such that they assemble $\mathrm{SiO}_{4}$ and $\mathrm{AlO}_{4}$ tetrahedral units forming a honeycomb structure with small pores about 0.1-2 nm diameter (Chester \& Derouane, 2009). Zeolite has a high ion exchange capacity, molecular sieve properties and also a high surface area.

Despite their individual effectiveness in heavy metal removal from aqueous solution, no studies have been carried out on boron removal using the combination of these three materials. Therefore, the effectiveness of mangrove-alginate-zeolite composite (MAZC) beads to remove boron from synthetic petrochemical wastewater is investigated in the present study. The surface characterizations of the beads were conducted using Fourier transform infrared spectroscopy (FTIR), Brunauer-Emmett Teller (BET) and scanning electron microscope with energy dispersive X-ray spectroscopy (EDX) before and after boron adsorption. Next, the adsorption performance of the beads was studied at different parameters such $\mathrm{pH}$, temperature, adsorbent dosage and contact time in batch experiments. Moreover, the thermodynamic, isotherm and kinetic studies were also evaluated.

\section{Sample collection}

\subsection{MATERIAL AND METHODS}

The wastewater was collected $100 \mathrm{~m}$ downstream from petrochemical refinery in Kerteh, Terengganu. The wastewater was stored in a cold room $\left(4^{\circ} \mathrm{C}\right)$ before used. Inductively coupled plasma optical emission spectrometry (ICP-OES) was used to determine the 
concentration of boron in the petrochemical wastewater. However upon analysis, it was found that the concentration of boron was only $0.351 \mathrm{mg} / \mathrm{L}$. This is due to the wastewater that could have been treated before collection. Since the concentration of boron was really low, the sample cannot be further used to run the experiment as it would not able to characterize the true performance of the adsorption process. In this regard, aqueous solution of boric acid, $\mathrm{H}_{3} \mathrm{BO}_{3}$ was used and its concentration was adjusted according to the real wastewater from the past study (Ariffin et al., 2012).

\section{Materials}

Aqueous solution of $\mathrm{H}_{3} \mathrm{BO}_{3}$ with concentration of $15 \mathrm{mg} / \mathrm{L}$ boron was prepared by using stock solution of $\mathrm{H}_{3} \mathrm{BO}_{3}$. The mangrove bark (Rhizophora Apiculata) was collected from a charcoal factory in Kuala Sepetang, Perak, Malaysia. Zeolite (clinoptilolite) used in this study was purchased from Avas Export-Import Malaysia Sdn Bhd. Sodium alginate was purchased from R\&M Chemicals (Selangor, Malaysia). Other chemicals such as sodium hydroxide, nitric acid, boric acid and calcium chloride were purchased from SYSTERM (Selangor, Malaysia).

\section{Preparation of adsorbent (MAZC)}

Firstly, the mangrove bark (MB) was extensively washed with distilled water before drying under sunlight for a few days to remove any contaminants. Next, the dried (MB) were then crushed, ground into small powder and sieved into $250 \mu \mathrm{m}$ sizes manually to increase its surface area. Next, $25 \mathrm{~g}$ of the sieved bark powder was chemically treated with $500 \mathrm{~mL}$ of $0.1 \mathrm{M}$ of $\mathrm{NaOH}$ for $2 \mathrm{~h}$ under continuous stirring at temperature between $50^{\circ} \mathrm{C}$ and $60^{\circ} \mathrm{C}$ to increase binding sites availability for maximum adsorption capacity (Emin Argun \& Dursun, 2006). The chemically modified (MB) were repeatedly washed again with distilled water until the $\mathrm{pH}$ of the solution became neutral. Then, the (MB) was filtered and oven-dried at $60^{\circ} \mathrm{C}$ for $24 \mathrm{~h}$. The dried (MB) powder was kept in separate glass containers until used and labeled as heated (MB) powder. For comparison, another (MB) powder was prepared using the same procedure, except for using thermal treatment during modification with $\mathrm{NaOH}$. Instead, the sieved (MB) powder was chemically treated with $\mathrm{NaOH}$ at room temperature. This dried (MB) powder was labeled as unheated (MB) powder.

The granular zeolite was crushed and sieved into $250 \mu \mathrm{m}$ sizes before being washed with distilled water followed by drying it in the oven at $120^{\circ} \mathrm{C}$ for $18 \mathrm{~h}$. The dried zeolite powder was kept in the glass container until used. For alginate solution, $5 \mathrm{~g}$ of sodium alginate powder was weighed and dissolved in $200 \mathrm{~mL}$ distilled water under vigorous stirring. Next, $2.5 \mathrm{~g}$ of heated (MB) powder was added slowly into alginate solution followed by $2.5 \mathrm{~g}$ of zeolite powder and were left under continuous stirring using a magnetic stirrer at $200 \mathrm{rpm}$. The mixture was left for $24 \mathrm{~h}$ until it became homogeneous. A syringe pump (New Era-300 pump system, USA) was then used to form the beads with the diameter of 3.5-4.0 mm as shown in Figure 1. Upon coming out of the $10 \mathrm{~mL}$ syringes, the beads were dropped into $200 \mathrm{~mL}$ of $2 \mathrm{M}$ of calcium chloride. The beads were then allowed to harden overnight. The resulting beads were then washed several times with distilled water to obtain neutral $\mathrm{pH}$ and later were allowed to dry on filter papers at room temperature for a few minutes. These beads were kept in glass containers for further experiments and labeled as heated MAZC beads. These steps were repeated using unheated (MB) powder and the resulting beads were assigned as unheated MAZC beads. 


\section{Characterization studies}

The initial and final concentration of boron was determined using inductively coupled plasma optical emission spectrometry (ICP-OES). The surface functional groups present in MAZC beads were determined using FTIR. The surface morphology of the adsorbents before and after adsorption process was conducted using SEM. The chemical compositions of MAZC beads were determined using EDX. The specific surface area and the pore distribution were measured using BET.

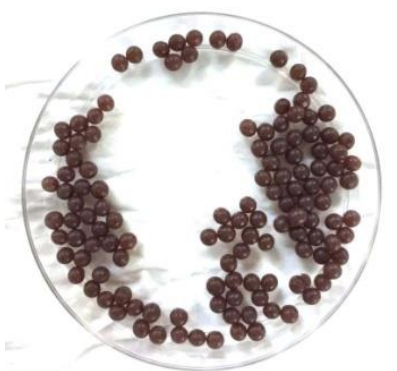

Figure 1: Picture of MAZC beads (3.5-4.0 mm).

\section{Batch adsorption studies}

In the batch studies, $50 \mathrm{~mL}$ of aqueous solution of $\mathrm{H}_{3} \mathrm{BO}_{3}$ was added into each beaker with a known weight of heated and unheated MAZC beads and were agitated using jar test and orbital shaker. This initial concentration of aqueous solution was fixed at $15 \mathrm{mg} / \mathrm{L}$ throughout the experiments. The $\mathrm{pH}$ of the solutions was varied using sodium hydroxide and nitric acid to obtain $\mathrm{pH}$ values ranging from 3 to 10 . The contact time was varied from $5 \mathrm{~min}$ to $24 \mathrm{~h}$. The effect of adsorbent dosage was studied in the range of 8-12 $\mathrm{g}$ of adsorbent. The effect of boron removal at temperature of $27^{\circ} \mathrm{C}$ and $40^{\circ} \mathrm{C}$ was evaluated. Upon completion of the adsorption process, the beads were filtered and the final concentrations of boron were analysed using ICP-OES. The removal percentage of boron was calculated according to Eq. (1) where $C_{i}$ and $C_{f}(\mathrm{mg} / \mathrm{L})$ are the initial and equilibrium concentrations of boron in aqueous solution.

$$
R(\%)=\frac{C_{i}-C_{f}}{C_{i}} X 100
$$

The adsorption capacities of the adsorbent at equilibrium were calculated using Eq. (2) where $\mathrm{q}_{\mathrm{e}}$ is the amount of boron adsorbed per unit mass of adsorbent $(\mathrm{mg} / \mathrm{g})$. W is the weight of beads used $(\mathrm{g})$ and $\mathrm{V}$ is the volume of aqueous solution (L).

$$
q_{e}=\left(\frac{C_{i}-C_{f}}{W}\right) V
$$

\subsection{RESULTS AND DISCUSSION}

\section{Surface characterization of MAZC beads}

Based on Figures 2 (a) and 3 (a), it can be seen that there is not much significant difference in terms of peaks because both beads were made of similar materials. Broad peaks were observed at frequency between $3381.43 \mathrm{~cm}^{-1}$ and $3379.63 \mathrm{~cm}^{-1}$ suggesting the presence of hydroxyl group (-OH stretch) that presented mainly in mangrove bark and sodium alginate. Besides, strong narrow peaks were also observed at adsorption bands 1638.21 $\mathrm{cm}^{-1}$ for heated MAZC beads and $1638.38 \mathrm{~cm}^{-1}$ for unheated beads, which indicate the presence of carboxyl group (symmetric -COO- stretching vibrations). Slightly different FTIR spectra were recorded before and after adsorption of boron which attributed to the 
reaction between aqueous solution and the functional groups on the surface of the adsorbent, resulting in the presence of new functional groups. After adsorption of boron, strong peaks spectrum of hydroxyl and carboxyl functional groups were still detected which indicate a very high concentration of these functional groups on the surface of MAZC beads. The bands which correspond to the $\mathrm{OH}$ groups have shifted to 3384.16 $\mathrm{cm}^{-1}$ and $3384.81 \mathrm{~cm}^{-1}$ after boron uptake. At frequency $1736.60 \mathrm{~cm}^{-1}$ and $1737.53 \mathrm{~cm}^{-1}$ for heated and unheated beads, respectively, sharp peaks were observed after boron adsorption which correspond to boron esters groups (C-O-C) (Bertagnolli et al., 2017). In addition, the appearance of the adsorption bands at $1368 \mathrm{~cm}^{-1}$ and $1372 \mathrm{~cm}^{-1}$ suggest the presence of the B-O link. Peak at frequency of $1030 \mathrm{~cm}^{-1}$ indicates the presence of asymmetric vibration of $\mathrm{Si}-\mathrm{O}$ or $\mathrm{Al}-\mathrm{O}$ which is assigned to zeolite compound on both surfaces of the beads (Suratman et al., 2017). Based on FTIR results, it can be seen that both hydroxyl and carboxyl functional groups are the main functional groups present on the surface of the MAZC beads which are responsible for the boron removal from aqueous solution.

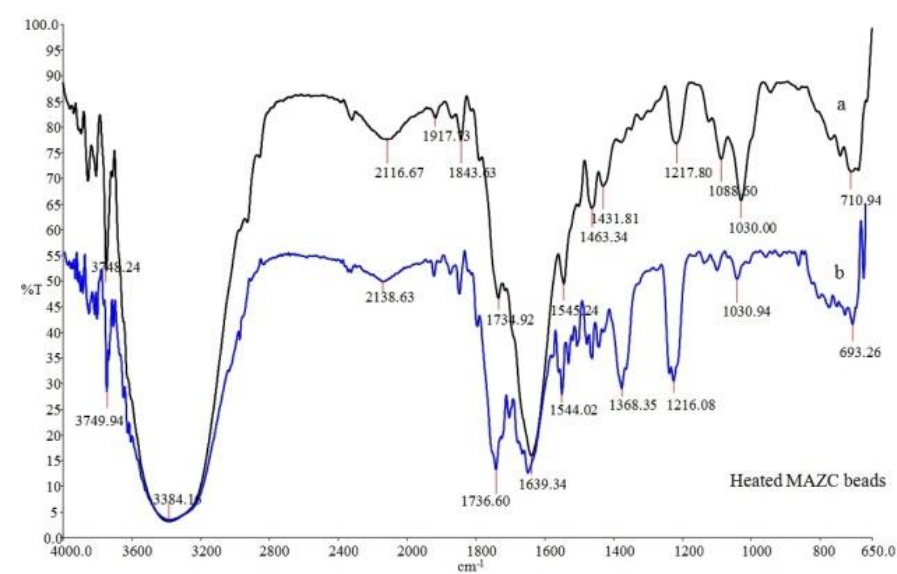

Figure 2: FTIR spectra of heated MAZC beads: a) before and b) after adsorption of boron.

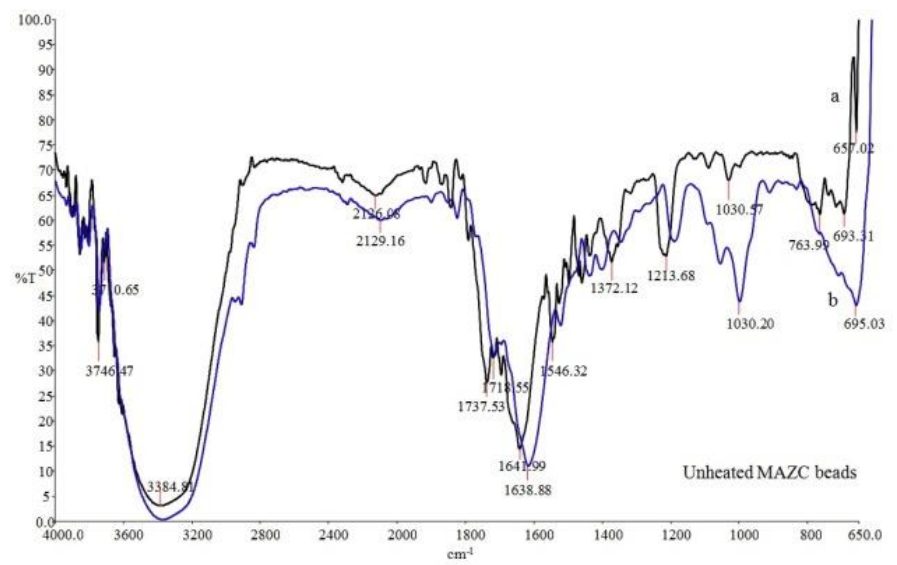

Figure 3: FTIR spectra of unheated MAZC beads: a) before and b) after adsorption of boron.

From the SEM analysis, the surfaces of both beads were physically uneven and rough as depicted in Figures 4 and 5. However, a more porous surface structure was observed on the surface of heated beads as compared with the unheated beads. Characteristics such as 
high surface roughness and high surface porosity could increase the percentage of boron uptake during adsorption process as the boron particles could easily get adsorbed on the beads surface (Wan et al., 2014). Morphologically, both beads showed rougher surfaces after boron uptake. Moreover, foreign particles were spotted on the surface which can be attributed to boron particles as shown in Figures 4 (b) and 5 (b).
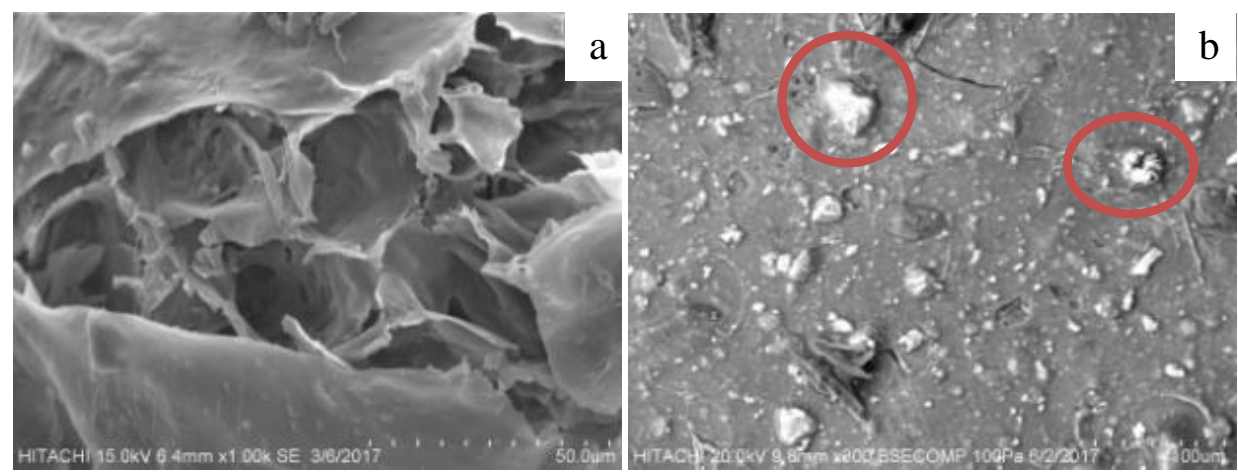

Figure 4: SEM images of heated MAZC beads: a) before and b) after adsorption of boron.

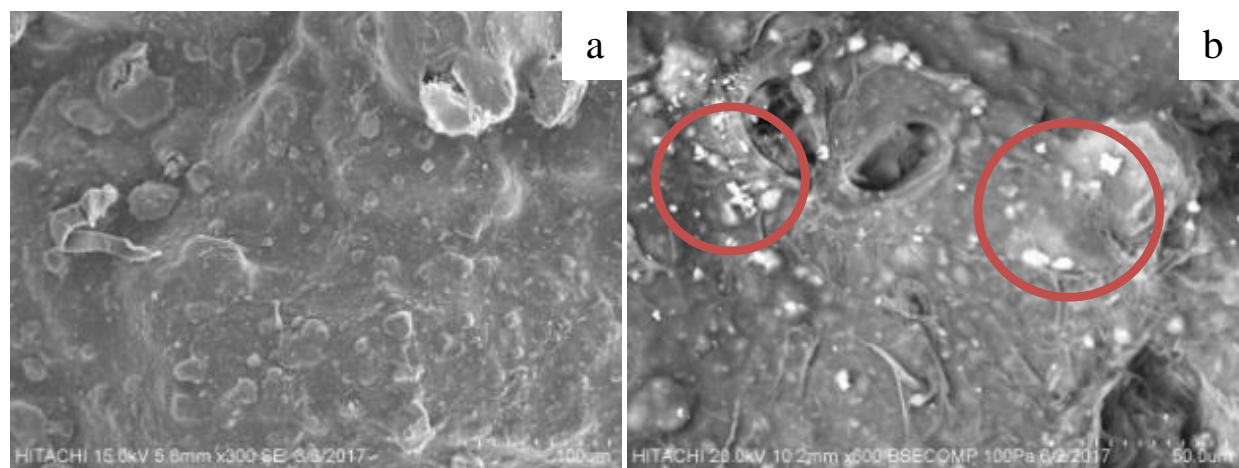

Figure 5: SEM images of unheated MAZC beads: a) before and b) after adsorption of boron.

EDX analysis before adsorption process showed that the carbon (C) content was the dominant element in the beads as they were made of mangrove bark and sodium alginate which contain a high amount of $\mathrm{C}$ content. Calcium $(\mathrm{Ca})$ can be found from EDX analysis as the beads were immersed in the calcium chloride solutions during the hardening process. A very small amount of potassium $(\mathrm{K})$ came from $\mathrm{NaOH}$ pellets that were used during pretreatment of mangrove bark. Other than that, $\mathrm{Al}$ and $\mathrm{Si}$ were also observed on the spectrum as both elements made up the chemical structure of natural zeolite, forming $\mathrm{SiO}_{4}$ and $\mathrm{AlO}_{4}$ tetrahedral structure. As expected, no boron was detected on both of the composite beads before the adsorption process as no reaction involving boron had yet taken place. From Table 1, heated MAZC beads were able to adsorb more boron as compared to unheated beads with $4.42 \%$ of B by mass. Thus, heated MAZC beads have better capacities for removal of boron from aqueous solution as compared to unheated composite beads.

The BET surface areas of heated and unheated MAZC beads before adsorption process were $13.4473 \mathrm{~m}^{2} / \mathrm{g}$ and $8.5740 \mathrm{~m}^{2} / \mathrm{g}$, respectively as shown in Table 2 . These surface areas were higher as compared to other adsorbents such as modified mangrove bark $\left(3.453 \mathrm{~m}^{2} / \mathrm{g}\right)$ (Rozaini et al., 2010) and sodium alginate $\left(3.974 \mathrm{~m}^{2} / \mathrm{g}\right.$ ) (Khan et al., 2014). Other than that, a high average pore diameter is also important to ensure the boron particles can be adsorbed into the adsorbent's pore. In this case, the pore diameters of 
both composite beads were large enough for adsorption of boron into the beads' pores. It is interesting to note that the surface area, pore volume and pore diameter of heated MAZC beads were higher than that of unheated beads which implied that the pretreatment of mangrove bark at higher temperature has improved the physical characteristics of the beads to increase the adsorption capacities by the composite beads.

Table 1: Chemical composition of MAZC beads before and after adsorption of boron.

\begin{tabular}{ccccccccc}
\hline & \multicolumn{3}{c}{ Before adsorption process } & \multicolumn{3}{c}{ After adsorption process } \\
\hline \multirow{3}{*}{ Element } & \multicolumn{3}{c}{ Heated MAZC } & \multicolumn{2}{c}{ Unheated MAZC } & \multicolumn{2}{c}{ Heated MAZC } & Unheated MAZC \\
\cline { 2 - 9 } & Mass & Atom & Mass & Atom & Mass & Atom & Mass & $\begin{array}{c}\text { Atom } \\
(\%)\end{array}$ \\
& $(\%)$ & $(\%)$ & $(\%)$ & $(\%)$ & $(\%)$ & $(\%)$ & $(\%)$ & $(\%)$ \\
\hline $\mathbf{C}$ & 58.70 & 73.88 & 57.59 & 73.16 & 52.99 & 63.50 & 57.56 & 73.42 \\
$\mathbf{O}$ & 16.04 & 15.16 & 16.23 & 15.48 & 14.26 & 15.52 & 15.63 & 14.60 \\
$\mathbf{A l}$ & 1.52 & 0.85 & 1.42 & 0.81 & 1.49 & 0.84 & 2.27 & 1.28 \\
$\mathbf{S i}$ & 7.14 & 3.84 & 6.95 & 3.77 & 8.91 & 4.76 & 6.63 & 3.53 \\
$\mathbf{K}$ & 0.38 & 0.15 & 0.31 & 0.12 & 0.53 & 0.21 & 0.34 & 0.13 \\
$\mathbf{C a}$ & 16.22 & 6.12 & 17.49 & 6.66 & 17.40 & 6.63 & 14.96 & 5.57 \\
$\mathbf{B}$ & 0.00 & 0.00 & 0.00 & 0.00 & 4.42 & 8.54 & 2.61 & 1.47 \\
\hline
\end{tabular}

Table 2: BET analysis on heated and unheated MAZC beads before and after adsorption of boron.

\begin{tabular}{ccccc}
\hline \multirow{2}{*}{ Properties } & \multicolumn{2}{c}{ Heated MAZC beads } & \multicolumn{2}{c}{ Unheated MAZC beads } \\
\cline { 2 - 5 } & Before & After & Before & After \\
\hline Surface area $\left(\mathrm{m}^{2} / \mathrm{g}\right)$ & 13.4473 & 0.1933 & 8.5740 & 0.3952 \\
Total pore volume $\left(\mathrm{cm}^{3} / \mathrm{g}\right)$ & 0.4646 & 0.0044 & 0.2496 & 0.0055 \\
Average pore diameter $(\mathrm{nm})$ & 138.217 & 91.108 & 116.463 & 56.269 \\
\hline
\end{tabular}

\section{Batch adsorption studies \\ Effect of $p H$}

In this study, the maximum percentage of boron removal from aqueous solution by heated MAZC was $83.3 \%$ which occurred at $\mathrm{pH}$ 5. For unheated MAZC, $65.2 \%$ of maximum boron removal was recorded at $\mathrm{pH} 7$. For heated MAZC beads, the percentage of boron removal increased proportionally with $\mathrm{pH}$ until reaching the optimum $\mathrm{pH}$ at $\mathrm{pH} 5$ before fluctuated between $\mathrm{pH} 6$ and 10 with the percentage of boron removal varied from $73.1 \%$ to $62.7 \%$. At $\mathrm{pH} 5$, both $\mathrm{H}^{+}$and $\mathrm{OH}^{-}$were in low concentrations to compete with borate ions which present in the solutions, thus favoured high boron uptake (Jalali et al., 2016). This finding was in agreement with the study conducted by Ariffin et al. (2012) when they found that the optimum $\mathrm{pH}$ for boron removal using chitosan also occurred at $\mathrm{pH} 5$ with $87.5 \%$ of boron were removed from raw wastewater. For unheated MAZC bead, more boron was removed as the $\mathrm{pH}$ of the solutions increased until it started to decrease after $\mathrm{pH} 7$ due to high competition between borate ions and $\mathrm{OH}^{-}$ions for adsorption sites. A similar optimum $\mathrm{pH}$ was also recorded during removal of boron using POMB ash (Chieng \& Chong, 2013). In the present experiment, the point of zero charge, $\mathrm{pH}_{\mathrm{zpc}}$ for heated and unheated MAZC beads were 7.74 and 7.20, respectively.

At low $\mathrm{pH}$ values, the carboxylic groups in alginate are mostly in - $\mathrm{COOH}$ form and boron exist in a neutral form, causing a very low interaction with the adsorbent (Demey-Cedeño et al., 2014). Also, at the acidic condition, ion exchange takes place between $\mathrm{H}^{+}$ions and 
$\mathrm{Ca}^{2+}$ ions in the beads due to a higher concentration of protons, reducing the adsorption of boron by the beads. At increasing $\mathrm{pH}$, the concentration of tetrahydroxyborate anion, $\mathrm{B}(\mathrm{HO})_{4}^{-}$increases and becomes the dominant species as shown in Eq. (3).

$$
\mathrm{B}(\mathrm{HO})_{3}+2 \mathrm{H}_{2} \mathrm{O} \leftrightarrow \mathrm{B}(\mathrm{HO})_{4}^{-}+\mathrm{H}_{3} \mathrm{O}^{+}
$$

Borate ions then react with $\mathrm{OH}$ - groups present in mangrove bark to form a strong complex through ligand exchange process (Jalali et al., 2016). Since the surface of the beads becomes positively charged at $\mathrm{pH}<\mathrm{pH}_{\mathrm{zpc}}$, a stronger force of attractions occurred between the negatively-charged borate ions and the positively-charged surface of the adsorbent which resulted in high boron uptake. On the other hand, at $\mathrm{pH}>\mathrm{pH}_{\mathrm{zpc}}$, the negatively charged adsorbent surface caused repulsion with $\mathrm{B}(\mathrm{HO})_{4}^{-}$, causing lower amount of boron uptake at higher $\mathrm{pH}$ which can be seen clearly as illustrated by unheated MAZC beads in Figure 5. Subsequent experiments were conducted at $\mathrm{pH} 5$ and $\mathrm{pH} 7$ for heated and unheated MAZC beads, respectively, in order to obtain maximum boron removal.

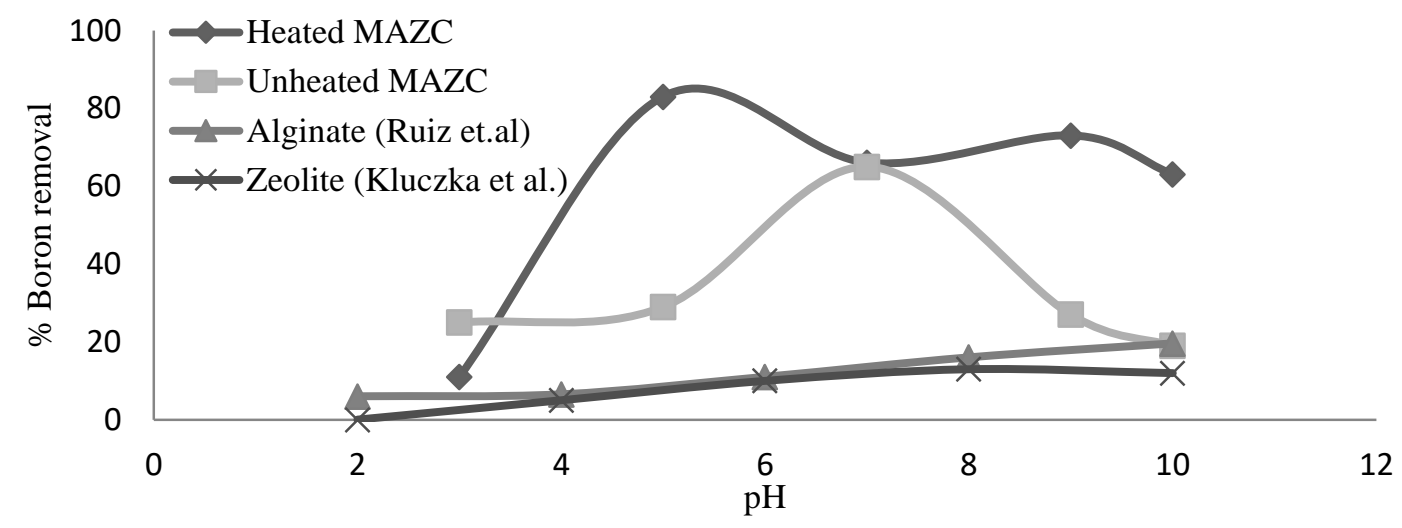

Figure 5: The effect of $\mathrm{pH}$ on the adsorption of boron.

Most studies reported the range of $\mathrm{pH}$ for effective boron removal take place around pH 5-9, depending on the type of adsorbent used (Guan et al., 2016). Ruiz et al. (2013) reported that the maximum $\mathrm{B}$ removal from solutions using calcium alginate beads occurred at pH 10 with over $25 \%$ of boron removal. Kluczka et al. (2013) found that the optimum $\mathrm{pH}$ for highest boron removal using natural zeolite occurred at $\mathrm{pH} 9$ with $13 \%$ of boron uptake.

\section{Effect of contact time}

For heated MAZC beads, the maximum boron removal was reached at $1440 \mathrm{~min}(24 \mathrm{~h})$ as graphed in Figure 6. At higher contact time, no significant changes in boron uptake were spotted. Thus, time contact of $24 \mathrm{~h}$ was accepted as the optimum time for the present study. For unheated MAZC beads, $61.9 \%$ of boron was removed from the solutions after 30 min contact time and remained almost constant even after being left for more than 24 $\mathrm{h}$. However, the maximum boron adsorption was recorded around $24 \mathrm{~h}$ with $65.2 \%$ of boron was removed from the solutions. Therefore, $24 \mathrm{~h}$ of contact time was used as the optimum time for the adsorption of boron by both heated and unheated MAZC beads. This trend is commonly observed from most of the studies involving removal of boron from wastewater such as using aquatic booster (Ismail et al., 2013) and fly ash zeolite (Kluczka et al., 2015). 


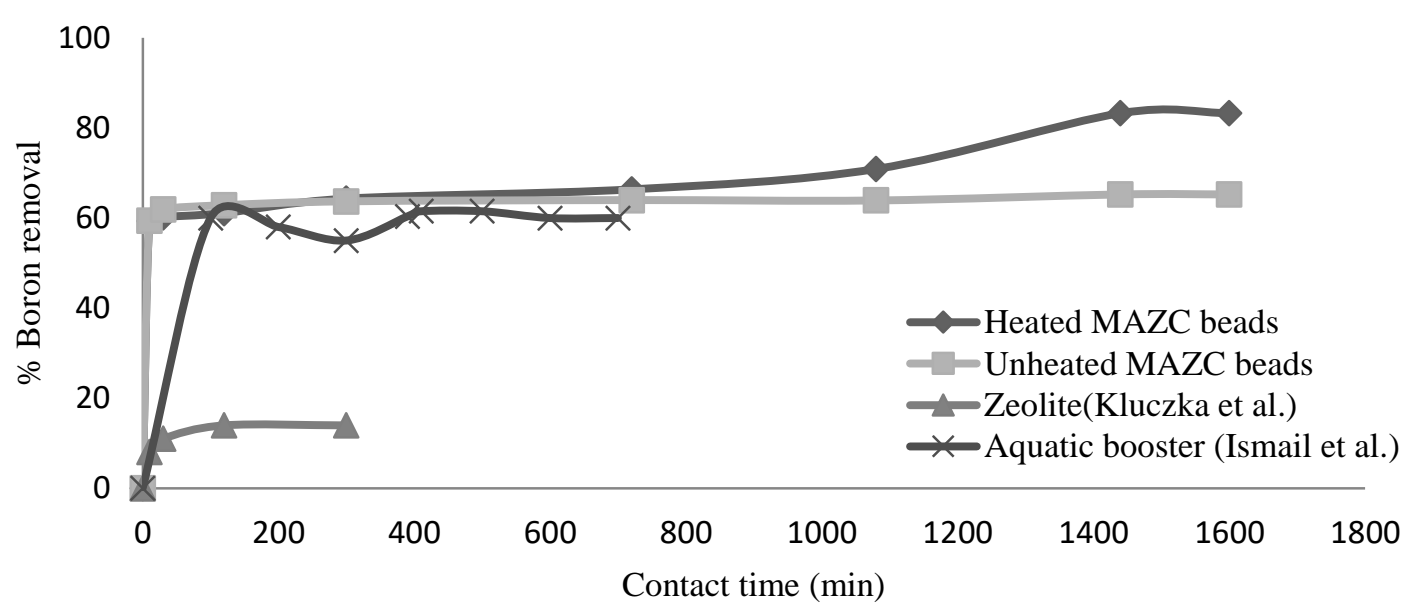

Figure 6: The effect of contact time on the adsorption of boron.

\section{Effect of adsorbent dosage}

From Figure 7, it can be seen that the percentage of boron removal increased when the amount of adsorbent increased which is in agreement with the past studies (Al.Haddabi et al., 2016; Polowczyk et al., 2013). This condition is attributed to the increase in the availability of adsorptions sites and greater surface area to adsorb borate ions. Since heated MAZC beads have greater pore diameter, more borate ions could be adsorbed into the pores at higher adsorbent dosages as compared to unheated MAZC beads. It was found that $12 \mathrm{~g}$ of heated MAZC beads managed to reduce boron concentration from $15 \mathrm{mg} / \mathrm{L}$ down to $2.507 \mathrm{mg} / \mathrm{L}$ which is below acceptable limit for discharge of industrial effluent set by Department of Environment. However, unheated MAZC beads unable to remove boron from the solutions to below the permissible limit at the same amount of adsorbent dosage, which indicate that the heated MAZC beads performed better and have higher adsorption capacities. Although increasing adsorbent dosage could possibly remove more boron from wastewater, $12 \mathrm{~g}$ of adsorbent dosage was accepted as optimum dosage for an economical reason as fewer amounts of beads will be used. Thus, $12 \mathrm{~g}$ of adsorbent dosage was used for subsequent experiments.

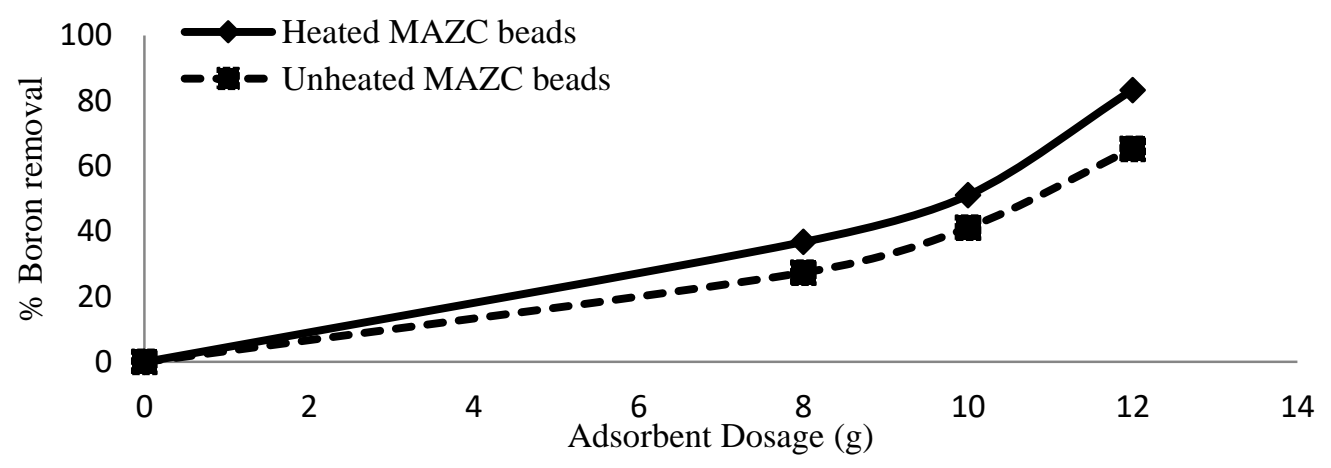

Figure 7: The effect of adsorbent dosage on the adsorption of boron.

\section{Effect of temperature and thermodynamics study}

The effect of temperature can be explained further by understanding the thermodynamics of the process by determining the thermodynamics parameters such as $\Delta G^{\circ}, \Delta H^{\circ}$ and $\Delta S^{\circ}$ using Eq.(4) where $\mathrm{R}$ is a gas constant $\left(8.314 \mathrm{~J} \mathrm{~mol}^{-1} \mathrm{~K}\right)$ and $\mathrm{T}$ is the absolute temperature in Kelvin (K). 


$$
\Delta G^{\circ}=-R T \ln K_{a}
$$

The equilibrium constant, $\mathrm{K}_{\mathrm{a}}$ values can be determined using standard enthalpy change, $\Delta H^{\circ}$ and standard entropy change, $\Delta S^{\circ}$ using Eq. (5).

$$
\ln K_{a}=\frac{\Delta S^{\circ}}{R}-\frac{\Delta H^{\circ}}{R T}
$$

The values of $\Delta H^{\circ}$ and $\Delta S^{\circ}$ were obtained from the slopes and intercepts of the Van't Hoff plots of $\ln \mathrm{K}_{\mathrm{a}}$ against 1/T. All the thermodynamics parameters are presented in Table 3. In the present study, it was found that the uptake of boron decreased with increasing temperature. A higher percentage of boron removal was recorded at room temperature $\left(27^{\circ} \mathrm{C}\right)$ as compared to at higher temperature $\left(40^{\circ} \mathrm{C}\right)$, indicating the exothermic nature of the adsorption process (Kavak, 2009). For heated and unheated MAZC beads, the calculated values of enthalpy change, $\Delta \mathrm{H}^{\circ}$ were $-90.8305 \mathrm{~kJ} / \mathrm{mol}$ and $-48.7608 \mathrm{~kJ} / \mathrm{mol}$, respectively. The negative values of $\Delta \mathrm{H}^{\circ}$ confirmed that the reaction was exothermic which showed that the process was stable energetically.

Previous studies also found boron removal by POMB ash (Chieng \& Chong, 2013) and fly ash zeolite (FAZ) (Joanna Kluczka et al., 2015) to be an exothermic adsorption process. The negative values of $\Delta \mathrm{S}^{\circ}$ suggest that the decrease in the randomness at the solid/solution interface during the boron uptake process. The negative values of $\Delta \mathrm{G}^{\circ}$ implied that the adsorptions of boron by MAZC beads at respective temperatures were spontaneous. In contrast, the positive $\Delta \mathrm{G}^{\circ}$ value indicates that the process was not spontaneous and required additional external energy to accelerate the reaction. In this study, the adsorption of boron by MAZC beads was more favourable at lower temperatures.

Table 3: Thermodynamic parameters of boron adsorption on MAZC beads at different

\begin{tabular}{|c|c|c|c|c|c|c|}
\hline \multirow[b]{2}{*}{$\begin{array}{c}\mathbf{T} \\
\left({ }^{\circ} \mathbf{C}\right)\end{array}$} & \multicolumn{3}{|c|}{ Heated MAZC beads } & \multicolumn{3}{|c|}{ Unheated MAZC beads } \\
\hline & $\Delta \mathrm{G}^{\circ}(\mathrm{kJ} / \mathrm{mol})$ & $\Delta \mathrm{H}^{\circ}(\mathrm{kJ} / \mathrm{mol})$ & $\begin{array}{c}\Delta \mathrm{S}^{\circ} \\
(\mathrm{kJ} / \mathrm{mol} \mathrm{K})\end{array}$ & $\Delta \mathrm{G}^{\circ}(\mathrm{kJ} / \mathrm{mol})$ & $\Delta \mathrm{H}^{\circ}(\mathrm{kJ} / \mathrm{mol})$ & $\begin{array}{c}\Delta \mathrm{S}^{\circ} \\
(\mathrm{kJ} / \mathrm{mol} \mathrm{K})\end{array}$ \\
\hline 27 & -4.0063 & & & -1.5719 & & \\
\hline 40 & -0.2458 & -90.8305 & -0.28927 & 0.4719 & -48.7608 & -0.15722 \\
\hline
\end{tabular}
temperatures.

\section{Adsorption equilibrium isotherm}

The study of adsorption isotherm is essential in giving further understanding on the mechanism of adsorption and determining the isotherm parameter such as maximum adsorption capacity of adsorbate for a given adsorbent. Two common adsorption isotherm models were employed in this study namely, the Langmuir and Freundlich. The Langmuir isotherm is based on the assumption that the adsorption process occurs on a homogeneous surface and there is no interaction between the adsorbed molecules. The linear form of Langmuir follows Eq. (6) where $\mathrm{q}_{\mathrm{e}}$ is the amount of boron adsorbed, $\mathrm{q}_{\max }$ is the maximum adsorption capacity, $\mathrm{K}(\mathrm{L} / \mathrm{mg})$ is the Langmuir affinity constant between the adsorbent and the adsorbate. $\mathrm{C}_{\mathrm{i}}$ and $\mathrm{C}_{\mathrm{f}}$ are the initial and equilibrium concentrations of boron in aqueous solution. 


$$
\frac{1}{q_{e}}=\frac{1}{q_{\max } K C_{f}}+\frac{1}{q_{\max }}
$$

Another important characteristic of the Langmuir isotherm is to determine the value of constant separation factor, $\mathrm{R}_{\mathrm{L}}$, given by Eq. (7) which indicates the reversibility of the isotherm. The isotherm is unfavorable if $R_{L}=1$, irreversible if $R_{L}=0$ and favourable if 0 $<\mathrm{R}_{\mathrm{L}}<1$ (Shavandi et al., 2012).

$$
R_{L}=\frac{1}{1+K C_{i}}
$$

The Freundlich isotherm describes the adsorption process occurs on a heterogeneous surface and each site has different adsorption energy (Hall et al., 1966). The Freundlich isotherm can be expressed according to Eq. (8) where $\mathrm{K}_{\mathrm{F}}$ and $\mathrm{n}$ are constants which indicate adsorption capacity and intensity, respectively. The $1 / \mathrm{n}$ value corresponds to the favourability of the isotherm where it is favourable if $0<1 / \mathrm{n}<1$.

$$
\log q_{e}=\log K_{F}+\frac{1}{n} \log C_{f}
$$

The linear forms of both models are graphically presented in Figures 8 and 9. The isotherm parameters for Langmuir and Freundlich models are presented in Table 4. The results showed that the adsorptions of boron on MAZC beads were better fitted to Langmuir isotherm model which provided a higher value of correlation coefficient, $\mathrm{R}^{2}$ as compared to Freundlich isotherm model. This indicates that the adsorption of boron occurred by monolayer adsorption on the homogeneous surface where there is no interaction between the adsorbed ions (Hall et al., 1966).

The maximum adsorption capacity, $\mathrm{q}_{\max }$ based on the Langmuir model for heated and unheated MAZC beads was $6.964 \mathrm{mg} / \mathrm{g}$ and $1.009 \mathrm{mg} / \mathrm{g}$, respectively. As expected, the heated MAZC beads have higher adsorption capacity as they can remove more boron as compared to unheated composite beads from the batch studies.

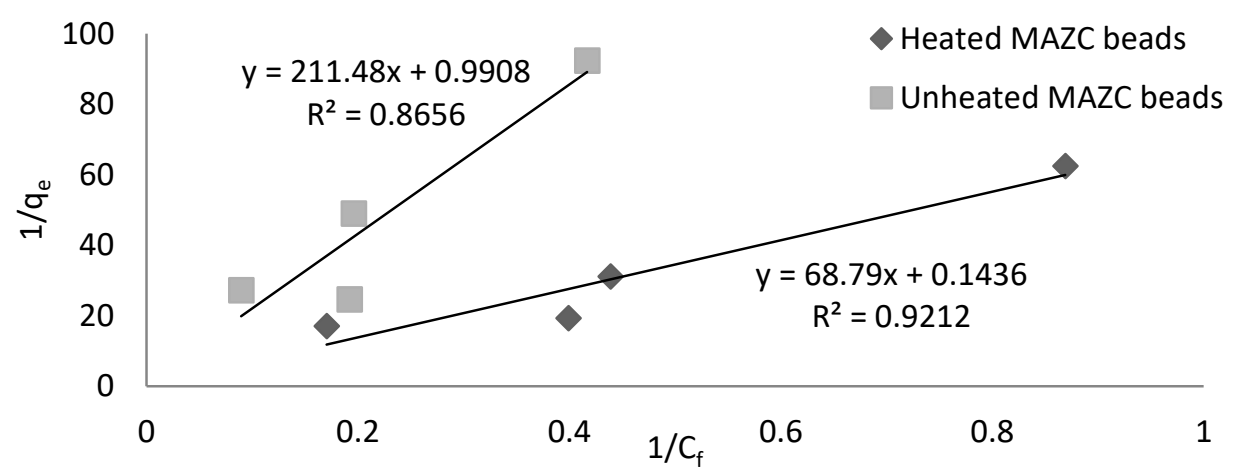

Figure 8: Langmuir adsorption isotherms of boron by MAZC beads. Conditions: $12 \mathrm{~g}$ dosage, $200 \mathrm{rpm}, 24 \mathrm{hrs}$ contact time, $27^{\circ} \mathrm{C}$. 


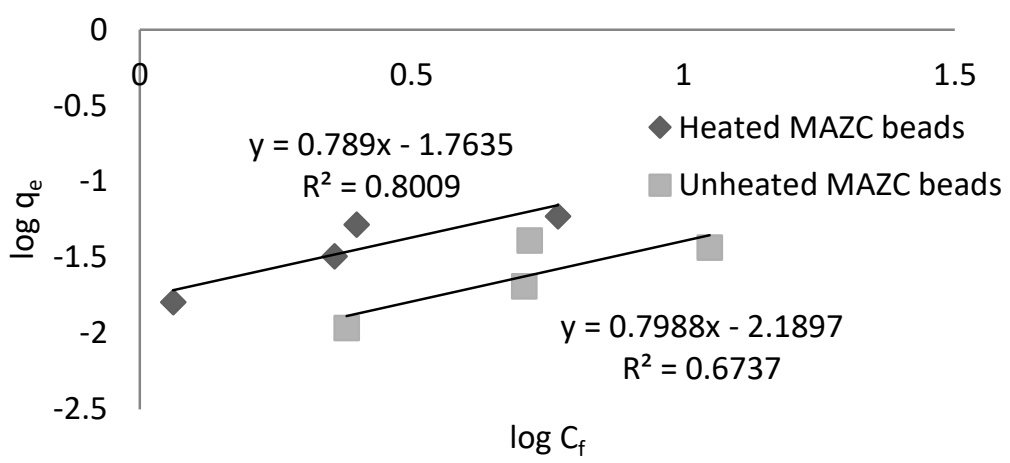

Figure 9: Freundlich adsorption isotherms of boron by MAZC beads. Conditions: $12 \mathrm{~g}$ dosage, $200 \mathrm{rpm}, 24 \mathrm{hrs}$ contact time, $27^{\circ} \mathrm{C}$.

The $R_{L}$ values for each initial concentration are tabulated in Table 5. All the $R_{L}$ values recorded lie between $0<\mathrm{R}_{\mathrm{L}}<1$ which implied that the adsorption of boron by MAZC beads is favourable. Since $\mathrm{R}_{\mathrm{L}}$ is inversely proportional to the initial concentration of boron solution, the decreasing trend of $\mathrm{R}_{\mathrm{L}}$ values was observed as the concentration of boron increased. For Freundlich isotherm, the $K_{\mathrm{f}}$ values calculated were $0.01724 \mathrm{mg} / \mathrm{g}$ and $0.00646 \mathrm{mg} / \mathrm{g}$ for heated and unheated MAZC beads, respectively. Moreover, $1 / \mathrm{n}$ values also lie between $0<1 / \mathrm{n}<1$, which confirms the favourability of the adsorption process.

Table 4: Isotherm parameters by Langmuir and Freundlich models.

\begin{tabular}{llcc}
\hline Isotherms & Parameters & Heated MAZC beads & Unheated MAZC beads \\
\hline \multirow{3}{*}{ Langmuir } & $\mathrm{R}^{2}$ & 0.9212 & 0.8656 \\
& $\mathrm{~K}(\mathrm{~L} / \mathrm{mg})$ & 0.00209 & 0.00469 \\
& $\mathrm{q}_{\max }(\mathrm{mg} / \mathrm{g})$ & 6.964 & 1.009 \\
\hline \multirow{3}{*}{ Freundlich } & $\mathrm{R}^{2}$ & 0.8009 & 0.6737 \\
& $\mathrm{~K}_{\mathrm{f}}(\mathrm{mg} / \mathrm{g})$ & 0.01724 & 0.00646 \\
& $1 / \mathrm{n}$ & 0.789 & 0.798 \\
\hline
\end{tabular}

Table 5: $\mathrm{R}_{\mathrm{L}}$ value for different initial concentrations of boron aqueous solution.

\begin{tabular}{lcccc}
\hline \multicolumn{1}{c}{ Initial Concentrations (mg/L) } & $\mathbf{5}$ & $\mathbf{1 0}$ & $\mathbf{1 5}$ & $\mathbf{2 0}$ \\
\hline $\mathrm{R}_{\mathrm{L}}$ for heated MAZC beads & 0.9897 & 0.9796 & 0.9696 & 0.9599 \\
\hline $\mathrm{R}_{\mathrm{L}}$ for unheated MAZC beads & 0.9771 & 0.9552 & 0.9343 & 0.9143 \\
\hline
\end{tabular}

\section{Kinetic Studies}

In order to evaluate the adsorption kinetics data on boron by MAZC beads, the pseudofirst order and pseudo-second order models are used in this study by varying the contact time during the adsorption process. Pseudo-first order describes the rate of change of solute uptake with time is directly proportional to the difference in saturation concentration and the amount of solid uptake with time (Khaled et al., 2009). A linear form of pseudo-first order can be expressed according to Eq. (9), where $\mathrm{q}_{\mathrm{e}}$ and $\mathrm{q}_{\mathrm{t}}$ are the adsorbed metal in $\mathrm{mg} / \mathrm{g}$ in the adsorbent at equilibrium, time, $\mathrm{t}$ and $\mathrm{k}_{1}$ is the constant of first-order adsorption $\left(\mathrm{min}^{-1}\right)$. The plot of $\log \left(\mathrm{q}_{\mathrm{e}}-\mathrm{q}_{\mathrm{t}}\right)$ against $\mathrm{t}$ can be used to determine the value of $\mathrm{k}_{1}$ and $\mathrm{q}_{\mathrm{e}}$.

$$
\log \left(q_{e}-q_{t}\right)=\log q_{e}-\frac{k_{1}}{2.303} t
$$


Pseudo-second order describes that the rate-limiting steps depend on the chemical forces of attraction and resemble the whole of the adsorption process. Pseudo-second order can be expressed according to Eq. (10) where $\mathrm{k}_{2}$ is the rate constant of second-order adsorption $\mathrm{g} / \mathrm{mg} \cdot \mathrm{min}, \mathrm{q}_{\mathrm{e}}$ is the amount of metal ions adsorbed at equilibrium and $q_{e}^{2}$ is the pseudo-second order adsorption rate constant. A straight line plot of $t / q_{t}$ against $t$ can be used to determine the value of $\mathrm{k}_{2}$ and $\mathrm{q}_{\mathrm{e}}$.

$$
\frac{t}{q_{t}}=\frac{1}{k_{2} q_{e}^{2}}+\frac{t}{q_{e}}
$$

The linear forms of the pseudo-first order and pseudo-second order models are depicted in Figures 10 and 11, respectively. Table 7 shows the kinetic parameters for both models. It can be observed that the pseudo-second order model gave an excellent correlation of the experimental data with high values of $\mathrm{R}^{2}$ of 0.9998 and 0.9831 for respective heated and unheated MAZC beads, respectively. Furthermore, the values of calculated $\mathrm{q}_{\mathrm{e}}$ were in a good agreement with the experimental data, qexp. Most of the past studies also found that the adsorption kinetics for boron removal by various adsorbents followed pseudosecond order expression as reviewed by Guan et al. (2016). Interestingly, the pseudo-first order model also provided a high value of $\mathrm{R}^{2}$ for the adsorption of boron by heated MAZC beads but lower value of $\mathrm{R}^{2}$ for unheated composite beads. From these results, it can be said that the adsorption of boron by heated MAZC beads suggests that both physisorption and chemisorption were the rate-determining steps during the whole process whereas, for unheated composite beads, the dominating process was the chemisorptions between boron and the adsorbent (Rozaini et al., 2010).

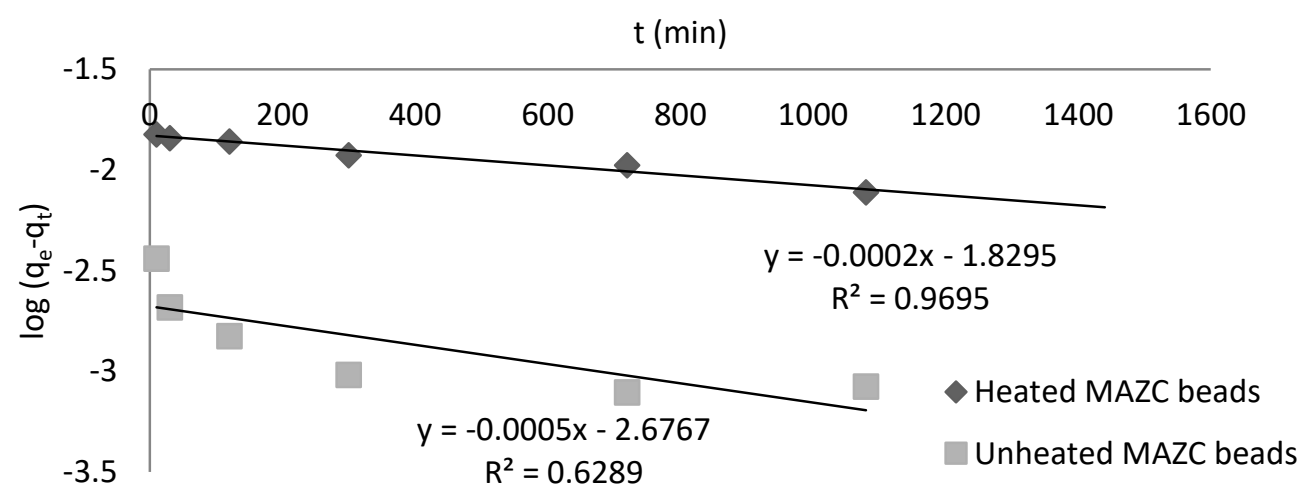

Figure 10: Kinetics of adsorption using pseudo-first order model for boron uptake by MAZC beads. Conditions: $15 \mathrm{mg} / \mathrm{L}$ concentration, $12 \mathrm{~g}$ dosage, $200 \mathrm{rpm}, 27^{\circ} \mathrm{C}$. 


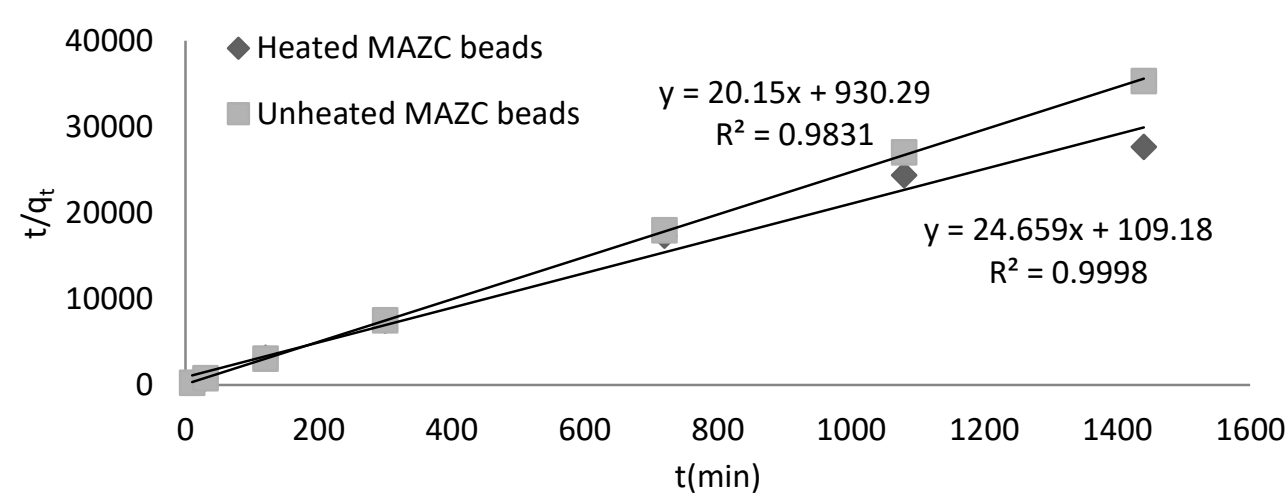

Figure 11: Kinetics of adsorption using pseudo-second order model for boron uptake by MAZC beads. Conditions: $15 \mathrm{mg} / \mathrm{L}$ concentration, $12 \mathrm{~g}$ dosage, $200 \mathrm{rpm}, 27^{\circ} \mathrm{C}$.

Table 7: Kinetic parameters for boron adsorption by MAZC beads.

\begin{tabular}{lccc}
\hline \multicolumn{1}{c}{ Models } & Parameters & Heated MAZC beads & $\begin{array}{c}\text { Unheated MAZC } \\
\text { beads }\end{array}$ \\
\hline Pseudo-first- & $\mathrm{R}^{2}$ & 0.9695 & 0.6289 \\
order & $\mathrm{k}_{1}\left(\mathrm{~min}^{-1}\right)$ & $4.61 \times 10^{-3}$ & $11.52 \times 10^{-3}$ \\
& $\mathrm{q}_{\mathrm{e}}(\mathrm{mg} / \mathrm{g})$ & 0.01481 & 0.00211 \\
\hline \multirow{2}{*}{ Pseudo- } & $\mathrm{R}^{2}$ & 0.9998 & 0.9831 \\
second-order & $\mathrm{k} \mathrm{k}_{2}(\mathrm{~g} /$ & 5.5693 & 0.436447 \\
& $\mathrm{mg} \cdot \mathrm{min})$ & 0.04055 & 0.04963 \\
\hline Experimental & $\mathrm{q}_{\mathrm{e}}(\mathrm{mg} / \mathrm{g})$ & 0.05205 & 0.04078 \\
\hline
\end{tabular}

\subsection{CONCLUSION}

The ability of heated and unheated MAZC beads to remove boron from its aqueous solution was investigated. It was found that heated MAZC beads can remove higher percentage of boron as compared to unheated beads. Pretreatment of mangrove bark at temperature $60^{\circ} \mathrm{C}$ has enhanced the characteristics of heated beads evident from SEM and BET analysis such as greater surface area and pore diameter. From FTIR study, hydroxyl and carboxyl groups were the key functional groups responsible for boron uptake. In addition, EDX analysis showed that boron element was found on the surface of the bead after adsorption process which indicates the ability of the composite beads to remove boron from aqueous solution. In the batch studies, the results showed that the adsorption of boron by MAZC beads was influenced by $\mathrm{pH}$, contact time, adsorbent dosage and temperature. With regard to the effect of $\mathrm{pH}$, the maximum boron removal of $83.3 \%$ was achieved by heated MAZC beads at $\mathrm{pH} 5$ and $65.2 \%$ by unheated MAZC beads at $\mathrm{pH} 7$. The optimum dosage was $12 \mathrm{~g}$ and the optimum contact time was $24 \mathrm{~h}$. Heated MAZC beads managed to reduce the final concentration of boron solution to $2.507 \mathrm{mg} / \mathrm{L}$ which meets the Malaysian discharged standard set by DOE. The thermodynamics studies revealed that the boron uptake decreased with an increase in temperature of the solution, indicating the exothermic nature of the adsorption process which is confirmed by the negative values of $\Delta \mathrm{H}^{\circ}$ for both beads. The experimental data were better fitted to the Langmuir isotherm as compared to the Freundlich model. The maximum adsorption capacities for heated and unheated MAZC beads were $6.964 \mathrm{mg} / \mathrm{g}$ and $1.009 \mathrm{mg} / \mathrm{g}$, respectively. The kinetic study showed that the pseudo-second order mechanism was the rate-determining steps for boron uptake by MAZC beads. These findings demonstrated that MAZC beads can be a potential adsorbent for the removal of boron from aqueous 
solution. An advantage of optimizing mangrove bark is the fact that it is natural, low-cost and found abundantly as a waste material from the timber industry.

\section{ACKNOWLEDGMENTS}

The authors wish to thank Universiti Putra Malaysia (UPM) for the financial support under research Grant Putra UPM (Vot. 9453200)

\section{REFERENCES}

Al.Haddabi, M., Ahmed, M., Al.Jebri, Z., Vuthaluru, H., Znad, H., \& Al.Kindi, M. (2016). Boron removal from seawater using date palm (Phoenix dactylifera) seed ash. Desalination and Water Treatment, 57(11), 5130-5137. http://doi.org/10.1080/19443994.2014.1000385

Ariffin, H., Hui, L. S., \& Zainura, Z. N. (2012). Removal of boron from industrial wastewater by chitosan via chemical precipitation. Journal of Chemical and Natural Resources Engineering, 4(1), 1-11.

Bertagnolli, C., Grishin, A., Vincent, T., \& Guibal, E. (2017). Boron removal by a composite sorbent: Polyethylenimine/tannic acid derivative immobilized in alginate hydrogel beads. Journal of Environmental Science and Health, Part A, 52(4), 359-367. http://doi.org/10.1080/10934529.2016.1260893

Chester, A. W., \& Derouane, E. G. (2009). Zeolite Characterization and Analysis : A Tutorial. (5th ed.) New York: Springer.

Chieng, H. J., \& Chong, M. F. (2013). Boron adsorption on palm oil mill boiler (POMB) ash impregnated with chemical compounds. Industrial and Engineering Chemistry Research, 52(41), 14658-14670. http://doi.org/10.1021/ie401215n

Demey-Cedeño, H., Ruiz, M., Barron-Zambrano, J. A., \& Sastre, A. M. (2014). Boron removal from aqueous solutions using alginate gel beads in fixed-bed systems. Journal of Chemical Technology \& Biotechnology, 89(1), 934-940. http://doi.org/10.1002/jctb.4361

Emin Argun, M., \& Dursun, Ş. (2006). Removal of heavy metal ions using chemically modified adsorbents. Journal International Environmental Application \& Science, 1(12), 27-40.

Foo, D. C. Y., \& Eng, C. (2015). The Malaysian chemicals industry : From commodities to manufacturing. American Institute of Chemical Engineers (AIChE), (November), 48-52. Retrieved from http://www.aiche.org/sites/default/files/cep/20151148.pdf

Guan, Z., Lv, J., Bai, P., \& Guo, X. (2016). Boron removal from aqueous solutions by adsorption - A review. Desalination, 383, 29-37. http://doi.org/10.1016/j.desal.2015.12.026

Hall, K. R., Eagleton, L. C., Acrivos, A., \& Vermeulen, T. (1966). Pore and solid-diffusion kinetics in fixedbed adsorption under constant-pattern conditions. I\&EC Fundamentals, 5(2), 212-223. http://doi.org/10.1021/i160018a011

Ismail, M. H. S., Zhang, X. T., \& Lazim, M. F. M. (2013). Removal of boron and arsenic from petrochemical wastewater by using aquatic booster as adsorbent. Polish Journal of Environmental Studies, 22(2), 403-408.

Jalali, M., Rajabi, F., \& Ranjbar, F. (2016). The removal of boron from aqueous solutions using natural and chemically modified sorbents. Desalination and Water Treatment, 57(18), 8278-8288. http://doi.org/10.1080/19443994.2015.1020509

Karahan, S., Yurdakoç, M., Seki, Y., \& Yurdakoç, K. (2006). Removal of boron from aqueous solution by clays and modified clays. Journal of Colloid and Interface Science, 293(1), 36-42. http://doi.org/10.1016/j.jcis.2005.06.048

Kavak, D. (2009). Removal of boron from aqueous solutions by batch adsorption on calcined alunite using experimental design. Journal of Hazardous Materials, 163, 308-314. http://doi.org/10.1016/j.jhazmat.2008.06.093

Khaled, A., El Nemr, A., El-Sikaily, A., \& Abdelwahab, O. (2009). Treatment of artificial textile dye effluent containing Direct Yellow 12 by orange peel carbon. Desalination, 238(1-3), 210-232. http://doi.org/10.1016/j.desal.2008.02.014

Khan, M. A., Gee, E., Choi, J., Kumar, M., Jung, W., Timmes, T. C., Kim, H. C., \& Jeon, B. H. (2014). Adsorption of cobalt onto graphite nanocarbon-impregnated alginate beads: Equilibrium, kinetics, and thermodynamics studies. Chemical Engineering Communications, 201(3), 403-418. http://doi.org/10.1080/00986445.2013.773426

Kluczka, J., Korolewicz, T., Zolotajkin, M., Simka, W., \& Raczek, M. (2013). A new adsorbent for boron removal from aqueous solutions. Environmental Technology, 34(11), 1369-1376. http://doi.org/10.1080/09593330.2012.750380

Kluczka, J., Trojanowska, J., \& Zołotajkin, M. (2015). Utilization of fly ash zeolite for boron removal from 
aqueous solution. Desalination and Water Treatment, 54(7), 1839-1849. http://doi.org/10.1080/19443994.2014.892033

Kluczka, J., Trojanowska, J., Zolotajkin, M., Ciba, J., Turek, M., \& Dydo, P. (2007). Boron removal from wastewater using adsorbents. Environmental Technology, 28(March), 105-113. http://doi.org/10.1080/09593332808618769

Mirbagheri, S. A., \& Hosseini, S. N. (2005). Pilot plant investigation on petrochemical wastewater treatment for the removal of copper and chromium with the objective of reuse. Desalination, 171(1), 85-93. http://doi.org/10.1016/j.desal.2004.03.022

Öztürk, N., \& Kavak, D. (2005). Adsorption of boron from aqueous solutions using fly ash: Batch and column studies. Journal of Hazardous Materials, 127(1-3), 81-88. http://doi.org/10.1016/j.jhazmat.2005.06.026

Papageorgiou, S. K., Katsaros, F. K., Kouvelos, E. P., Nolan, J. W., Le Deit, H., \& Kanellopoulos, N. K. (2006). Heavy metal sorption by calcium alginate beads from Laminaria digitata. Journal of Hazardous Materials, 137(3), 1765-1772. http://doi.org/10.1016/j.jhazmat.2006.05.017

Polowczyk, I., Ulatowska, J., Ko, T., Bastrzyk, A., \& Sawi, W. (2013). Studies on removal of boron from aqueous solution by fly ash agglomerates. Desalination, 310, 93-101. http://doi.org/10.1016/j.desal.2012.09.033

Rahmawati, K., Ghaffour, N., Aubry, C., \& Amy, G. L. (2012). Boron removal efficiency from Red Sea water using different SWRO/BWRO membranes. Journal of Membrane Science, 423-424, 522-529. http://doi.org/10.1016/j.memsci.2012.09.004

Rozaini, C. A., Jain, K., Oo, C. W., Tan, K. W., Tan, L. S., Azraa, A., \& Tong, K. S. (2010). Optimization of nickel and copper ions removal by modified mangrove barks. International Journal of Chemical Engineering and Applications, 1(1), 84-89.

Ruiz, M., Tobalina, C., Demey-Cedeño, H., Barron-Zambrano, J. A., \& Sastre, A. M. (2013). Sorption of boron on calcium alginate gel beads. Reactive and Functional Polymers, 73(4), 653-657. http://doi.org/10.1016/j.reactfunctpolym.2013.01.014

Sari, M. A., \& Chellam, S. (2015). Mechanisms of boron removal from hydraulic fracturing wastewater by aluminum electrocoagulation. Journal of Colloid and Interface Science, 458, 103-11. http://doi.org/10.1016/j.jcis.2015.07.035

Shavandi, M. A., Haddadian, Z., Ismail, M. H. S., Abdullah, N., \& Abidin, Z. Z. (2012). Removal of Fe (III), Mn (II) and Zn (II) from palm oil mill effluent (POME) by natural zeolite. Journal of the Taiwan Institute of Chemical Engineers, 43(5), 750-759. http://doi.org/10.1016/j.jtice.2012.02.014

Shih, Y. J., Liu, C. H., Lan, W. C., \& Huang, Y. H. (2014). A novel chemical oxo-precipitation (COP) process for efficient remediation of boron wastewater at room temperature. Chemosphere, 111, 232237. http://doi.org/10.1016/j.chemosphere.2014.03.121

Suratman, A., Kunarti, E. S., Aprilita, N. H., \& Pamurtya, I. C. (2017). Adsorption of $\mathrm{CO}_{2}$ by alginate immobilized zeolite beads. American Institute of Physics, 1823, 20118-1-20118-8. http://doi.org/10.1063/1.4978191

Thompson, R. (1974). Industrial applications of boron compounds. Pure and Applied Chemistry, 39(4), 547559. http://doi.org/10.1351/pac197439040547

Wan, S., Ma, Z., Xue, Y., Ma, M., Xu, S., Qian, L., \& Zhang, Q. (2014). Sorption of lead(II), cadmium(II), and copper(II) ions from aqueous solutions using tea waste. Industrial and Engineering Chemistry Research, 53(9), 3629-3635. http://doi.org/10.1021/ie402510s

Yilmaz, A. E., Boncukcuoglu, R., Yilmaz, M. T., \& Kocakerim, M. M. (2005). Adsorption of boron from boron-containing wastewaters by ion exchange in a continuous reactor. Journal of Hazardous Materials, 117(2-3), 221-226. http://doi.org/10.1016/j.jhazmat.2004.09.012

Yürüm, A., Taralp, A., Biçak, N., Özbelge, H. Ö., \& Yilmaz, L. (2013). High performance ligands for the removal of aqueous boron species by continuous polymer enhanced ultrafiltration. Desalination, 320, 33-39. http://doi.org/10.1016/j.desal.2013.04.020 